\title{
RESIDENT INVOLVEMENT IN INSPECTING TREES FOR DUTCH ELM DISEASE
}

\author{
by Dawn K. Nannini, ${ }^{2}$ Robert Sommer, ${ }^{1}$ and Lawrence S. Meyers ${ }^{3}$
}

\begin{abstract}
This study investigated the costs and benefits of a public-private partnership in the monitoring of mature elm trees threatened by Dutch elm disease (Ceratocystis ulmi). To compensate for a budget shortfall, the Sacramento Tree Foundation began its Save The Elms Program (STEP), which enlisted the help of volunteers for the early detection of Dutch elm disease. Of the 269 residents who initially expressed interest in the program, only half received training due to scheduling difficulties and time constraints. A mail survey compared the knowledge and attitudes of trained volunteers and those who volunteered but did not receive training. While all respondents endorsed the importance of street trees to the area, those with training were more knowledgeable about their local urban forest and were more satisfied with their neighborhoods.
\end{abstract}

Keywords. Dutch elm disease; inspection; volunteers

Dutch elm disease (Ceratocystis ulmi; DED) represents a significant threat to the elm population in many U.S. cities. Lacking a cost-effective treatment for the disease, the best available method is careful monitoring followed by quick removal of infected trees. The city of Minneapolis, Minnesota, provides an excellent example for the success of this method. Approximately 130,000 elm trees were in existence when DED first appeared in Minneapolis in the 1960s. Early losses were low, less than 10 per year. Little was done to address the problem, and the infestation quickly spread. From a loss of several hundred trees in 1972, thousands were lost in 1975, with a peak of 31,000 mature trees lost in 1977. The city responded by increasing funds for urban forestry and starting a citizen "Elm Tree Watch" program that has succeeded in bringing losses down to approximately 3,000 trees per year, a rate considered to be manageable by city authorities (Gemmill et al. 1995; Gruber and Shelton 1987; Sia 1994).

DED was first noted in California in 1975 and was confined largely to the San Francisco Bay Area. In the early 1990s, the 1st case of DED was detected in Sacramento County. The state of California, which had been monitoring the progress of the disease, terminated its DED control program in 1993 due to a budget shortfall, leaving the state vulnerable to a major infestation of a valuable tree resource. To compensate, the Sacramento Tree Foundation, supported by the city council and local businesses, started the Save The EIms Program (STEP). The Sacramento Municipal Utility District distributed 20,000 brochures in elm-dominant neighborhoods asking for volunteers to conduct periodic tree inspections.

Two-hundred sixty-nine residents initially expressed interest in joining the community effort to protect local elms, but due to scheduling conflicts and time constraints only half of them received the training. Participants received a full day of small group training after which they "adopted" areas (containing an average of $35 \mathrm{elm}$ trees each) in their neighborhoods.

Throughout the year, but most intensively during spring and summer, these volunteers examined trees and reported on their conditions to the Sacramento Tree Foundation. Since the volunteer program's inception, the number of trees infected with DED has steadily decreased from 24 in 1994 to 8 in 1996 (Pskowski 1994, 1995, 1996).

Resident participation in community programs increasingly provides an economical way to monitor elms during this era of shrinking municipal budgets. The National Research Agenda for Urban Forestry considers resident involvement to be critical to the continued vitality of the urban forest in the 1990s. An alliance of professionals and volunteers is potentially more cost effective and successful in monitoring tree conditions than either group operating by itself. Strategies for using volunteers to conduct urban forest resource inventories are available in the literature (Buchanan 1991; Monear 1993; Probart 1993). A systematic comparison in Brookline, Massachusetts, found that data collected by trained volunteers were valid and that the accuracy compared fa- 
vorably with levels found among a control group of Certified Arborists (Bloniarz and Ryan 1996). An additional benefit was the development of a more informed urban forest constituency. Extending this research, the current study investigated the effects of community participation in tree maintenance on volunteers' knowledge of their urban forest, attitudes towards their community, and attitudes toward volunteering for a community effort.

\section{Method}

All of the survey respondents lived in elm-treedominant neighborhoods and had responded to an invitation to participate in STEP. Invitations had been distributed through the mail by the Sacramento Municipal Utility District.

A total of 269 residents initially expressed interest in joining the program, but only half of them actually received training and began work in the program. This provided the opportunity for a systematic comparison of knowledge and attitude among those residents who volunteered for the program and received the training with those who volunteered but mostly for reasons of schedule were unable to receive training. STEP participants received a full day of small group training after which they adopted areas in their neighborhood containing an average of $35 \mathrm{elm}$ trees each. Throughout the year, but primarily during spring and summer, these volunteers examined trees and reported on their conditions to the Sacramento Tree Foundation.

Mail survey. This study began a year after the start of the community project. A questionnaire was developed to investigate the effects of community participation on volunteers' knowledge of their urban forest, attitudes towards their community, and attitudes toward volunteering. The survey was mailed to the same 269 residents who expressed initial interest in STEP.

The 1st section contained a series of statements that indirectly addressed individuals' sense of community and sense of empowerment. Respondents were asked to rate the extent to which they agreed with each of the statements using a 5-point scale ranging from 1 (strongly agree) to 5 (strongly disagree). For respondents who partic- ipated in the training, questions addressed individuals' motivation for becoming a volunteer, satisfaction with the training, and experiences in the program. Most of these questions were also included on the questionnaire for the nonparticipant group, with the exception of those questions that addressed actual tree inspections and followup.

The 2nd section of the survey contained a neighborhood satisfaction measure adapted from the neighborhood attractiveness factor of Gruber and Shelton's (1987) Resident Satisfaction Scale. Participants responded to 8 items, using a 4-point scale ranging from 1 (very satisfied) to 4 (very dissatisfied). In addition, participants were given the option of "no opinion" on each of the items.

The 3rd section of the questionnaire included 9 multiple-choice questions that assessed individuals' knowledge of Dutch elm disease and the local urban forest. Instructions at the top of the page requested respondents not to consult materials received during the training. The final section of the questionnaire included openended questions that gave participants the opportunity to offer input concerning the strengths and weaknesses of the program.

The envelopes in which the surveys were mailed and the cover letters that accompanied the surveys were highly personalized to increase the return rate of the questionnaires. Attractive, 1st-class postage stamps were used on both the exterior and the return envelope. The resident's address was handwritten in blue ink, the cover letter was personally signed by the principal researchers, and a personal statement of thanks was included at the bottom of the cover letter. Each questionnaire was numbered so that returns could be monitored.

Three weeks after the initial mailing, a followup letter containing another copy of the groupappropriate questionnaire and a stamped return envelope were sent to all of the individuals who neglected to respond to the 1st mailing, excluding those whose questionnaires had been returned as undeliverable. The return rate of delivered questionnaires for the entire sample of respondents was $45 \%$, consisting of $49 \%$ for the trained group and $40 \%$ for the untrained group. 
With respect to the 2 groups - those who participated in the training and adopted trees and those who were unable to participate in the trainingthere was no difference in the gender composition, the age of the respondents, or their length of residence in Sacramento or their present neighborhoods.

\section{Results}

Concerns of nonrespondent bias were addressed by comparing early and late returns. Responses of individuals who did not respond to the 1st mailing but subsequently responded to the followup survey were compared with the responses of individuals who responded to the 1st mailing. A multivariate analysis of variance, evaluated against the Wilk's Lambda criterion, indicated no significant differences between early and late returns, $F(1,106)=1.08, p>.05$.

Attitude toward STEP. A multivariate analysis of variance, evaluated against the Wilk's Lambda criterion, was used to investigate differences in individuals' attitude toward the STEP program among those who participated in STEP and those who did not, $F(1,111)=9.35, p<.001$.
A Bonferroni correction used to evaluate univariate tests showed $p<.006(.05 / 9)$. Table 1 contains the means $(\bar{x})$, standard deviations $(\sigma)$, and univariate $F$ ratios for the participant and nonparticipant groups on the dependent measures used in the multivariate analysis of variance.

Both groups almost unanimously endorsed the importance of trees to the Sacramento area and agreed that healthy trees were important to their neighborhoods. This point is particularly important because it suggests that differences found between participants and nonparticipants should not be attributed to an inherent disparity in the value placed on greenery in their community.

A somewhat unexpected divergence between those who participated in STEP and those who did not was the extent to which they believed that participation in STEP afforded an opportunity to meet new people. Generally, participation in a community project requires some degree of interaction among the volunteers. STEP, however, did not lend itself to socializing. With the exception of an afternoon of training, volunteers had no formal contact with each other. Responses to open-ended questions revealed a strong desire

Table 1. Means, standard deviations, and universal $F$ ratios for participant and nonparticipant groups on dependent measures in the multivariate analysis of variance describing differences in individuals' attitudes towards STEP $(n=108)$.

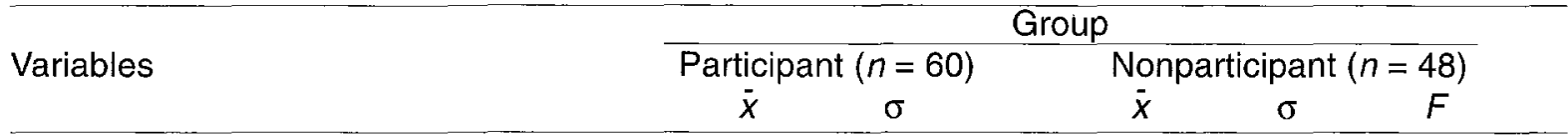

Value of urban greenery

Trees important to Sacramento

$\begin{array}{lllll}5.00 & 0.00 & 4.84 & 0.80 & 2.49 \\ 4.94 & 0.31 & 4.80 & 0.80 & 1.42\end{array}$

Important that trees are healthy

$4.94 \quad 0.31$

4.80

1.42

Attitudes toward STEP

STEP volunteers are effective

Volunteers supported/appreciated

4.24

0.76

4.00

1.13

1.83

Valuable skills to be learned in STEP

4.19

0.85

3.73

0.92

$7.93^{*}$

4.18

0.90

3.94

1.07

1.64

Foresee participating in future

3.73

1.90

3.56

1.15

0.38

Opportunity to meet new people

2.48

0.97

3.73

0.87

$50.07^{* *}$

Like people who share interests

3.52

1.10

3.61

0.92

0.23

Encourage friends to do STEP

2.90

1.05

3.12

0.82

1.42

Note: For all of the dependent variables, scores ranged from $0-5$; higher values indicated more of the respective attributes.

${ }^{*} p<.006$

${ }^{* *} p<.001$ 
among the volunteers for routine meetings that would give them a chance to interact with each other.

STEP participants felt that their work was supported and appreciated more than did nonparticipants. Participants also believed that their efforts contributed to the prevention of DED and that they had learned valuable skills as a result of their participation in STEP.

Over $85 \%$ of those who volunteered for the community effort indicated that they were motivated by their concern for Sacramento's trees. Of the reasons provicled by nonparticipants, only $9 \%$ cited a disinterest in contributing to the efforts of the community project, while the majority named scheduling difficulties and time constraints as the primary obstacle to participation in STEP.

Neighborhood satisfaction. Individuals' satisfaction with their neighborhood was determined by averaging the responses to items from the neighborhood attractiveness factor of Gruber and Shelton's (1987) Resident Satisfaction Scale. As shown in Figure 1 ( 8 items; $\alpha=.92$ ), a 1-way analysis of variance indicated that individuals who participated in STEP were significantly more pleased with their neighborhoods than were those who did not participate in STEP, $F(1,117)=4.75$, $p<.05$.

Knowledge of DED and the local urban forest. Individuals' knowledge was determined by the number of correct responses to 9 multiplechoice questions about Dutch elm disease and trees characteristic of the Sacramento area ( 9 items; $\alpha=.64)$. STEP volunteers were significantly more knowledgeable about Sacramento's

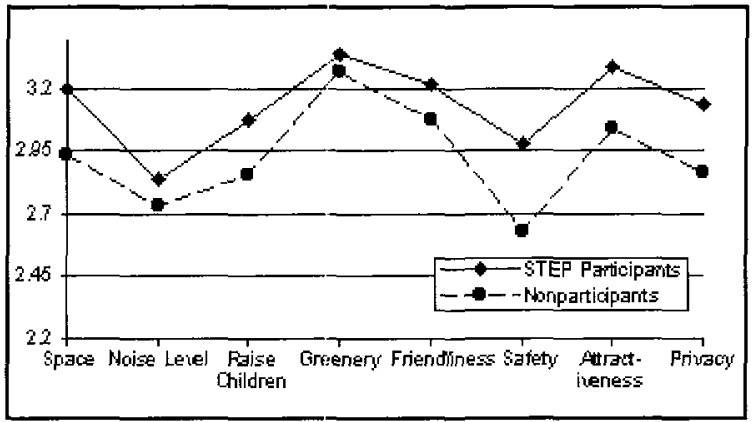

Figure 1. Extent to which individuals were satisfied with 8 neighborhood characteristics. urban forest than were individuals who did not participate in STEP, $F(1,118)=52.24, p<.001$.

Volunteers answered an average of $5.10(\sigma=$ 2.05) questions correctly compared to an average of $2.59(\sigma=1.68)$ answered correctly by those who did not participate in STEP.

\section{Discussion}

STEP was able to cut costs in curbing the spread of DED in Sacramento through early detection by enlisting the help of volunteers. Participation in the program appeared to positively influence individuals' perception of their neighborhoods. Not only were STEP participants more knowledgeable about the local urban forest than were individuals who were unable to participate, their participation in the maintenance of the health of urban trees was associated with more positive views of their own neighborhoods. The greater satisfaction with their neighborhoods shown by the STEP participants is particularly interesting in that other researchers have been unable to obtain a relationship between evaluations of neighborhood aspects and participation in other types of community projects. A major difference in the current study, however, is that participants' direct action in maintaining the health of city trees affected more than just the yards in which the trees were planted-it affected the entire neighborhood. Large trees form canopies over streets lending the appearance of cohesive neighborhoods. Just as direct action in the planting of trees positively influences homeowners' perception of the yard (Sommer 1996), so the maintenance of mature trees positively influenced participants' perception of their neighborhood.

Despite their expressed disappointment in not having had opportunities to meet with other volunteers throughout the season, individuals' experiences with this program were extremely positive. Volunteers believed that their efforts were worthwhile, both because they felt that their work was appreciated and that they had contributed to the prevention of the infectious fungus among Sacramento's elms. Aside from their contribution to the program, volunteers also believed that they had learned valuable skills. Community education benefits the entire urban forest by 
equipping individuals with the knowledge and skills necessary for the maintenance of healthy, mature trees.

When both parties have a vested interest in a public-private partnership in preserving valuable greenery, their collaboration may potentially contribute not only to stronger trees but also to stronger communities. Dwyer and Schroeder (1994) suggested that actions that begin with tree planting may spread to other aspects of the community and result in stronger economic and social development. While the planting of new trees represents a fresh start in the development of the community, it is not sufficient to get trees into the ground if there are no provisions for maintenance. The maintenance of older, more mature trees represents the community's interest in sustaining valued greenery and strong community ties.

\section{Literature Cited}

Bloniarz, D.V., and H.D.P. Ryan. 1996. The use of volunteer initiatives in conducting urban forest resource inventories. J. Arboric. 22 (2):75-82.

Buchanan, E.L. 1991. Who should conduct tree inventories?, pp. 155-158. In American Forests (Ed.). 5th National Urbian Forest Conference, Los Angeles, CA.

Dwyer, J., and H. Schroeder. 1994. The human dimensions of urban forestry. J. Forestry. 92:12-15.

Gemmill, B., A. Fenkner, M. Ferri, and S. Williams. 1995. Stewardship of the mature elm tree canopy in Sacramento through citizen participation. Paper presented at the Conference on Benefits of the Urban Forest, Sacramento Tree Foundation, March 7.
Gruber, K.J., and G.G. Shelton. 1987. Assessment of neighborhood satisfaction by residents of three housing types. Soc. Indicat. Res. 19:303-315.

Monear, J. 1993. Volunteer pro's and con's: The seven C's of success, pp. 132-134. In American Forests (Ed.). 6th Annual Urban Forest Conference, Minneapolis, MN.

Probart, S. 1993. Effective volunteerism, pp. 49-50. In American Forests (Ed.). 6th Annual Urban Forest Conference, Minneapolis, MN.

Pskowski, D. 1994. City of Sacramento Tree Services Department Internal Logs. Unpublished raw data.

Pskowski, D. 1995. City of Sacramento Tree Services Department Internal Logs. Unpublished raw data.

Pskowski, D. 1996. City of Sacramento Tree Services Department Internal Logs. Unpublished raw data.

Sia, N. 1994. Street tree planting in Sacramento neighborhoods: An evaluation. In Francis, M., Lindsey, P., and Rice, J.S. (Eds). The Healing Dimensions of People-Plant Relations. UCD Center for Design Research, Davis, CA.

Sommer, R. 1996. The value of resident participation in tree planting. Arborist News. (5)6:43-44.

'Psychology Department

University of California

Davis, CA 95616

${ }^{2}$ Graduate Student in Psychology

California State University, Sacramento

${ }^{3}$ Professor of Psychology

California State University, Sacramento 